\title{
The role of Leishmania proteophosphoglycans in sand fly transmission and infection of the mammalian host
}

\section{Matthew E. Rogers*}

Faculty of Infectious Tropical Diseases, Department of Immunology and Infection, London School of Hygiene and Tropical Medicine, London, UK

\section{Edited by:}

Nathan Peters, National Institute of

Allergy and Infectious Diseases, USA

\section{Reviewed by:}

Jie Sun, Indiana University School of Medicine, USA

Xun Suo, China Agricultural

University, China

Gregory Lanzaro, University of

California, USA

\section{*Correspondence:}

Matthew E. Rogers, Faculty of Infectious Tropical Diseases,

Department of Immunology and Infection, London School of Hygiene and Tropical Medicine, Keppel Street London WC1E 7HT, UK.

e-mail:matthew.rogers@Ishtm.ac.uk
Leishmania are transmitted by the bite of their sand fly vector and this has a significant influence on the virulence of the resulting infection. From our studies into the interaction between parasite, vector, and host we have uncovered an important missing ingredient during Leishmania transmission. Leishmania actively adapt their sand fly hosts into efficient vectors by secreting Promastigote Secretory Gel (PSG), a proteophosphoglycan (PPG)-rich, mucin-like gel which accumulates in sand fly gut and mouthparts. This has the effect of blocking the fly, such that during bloodfeeding both parasites and gel are co-transmitted in an act of regurgitation. We are discovering that this has further implications for the mammalian infection, again, in favor of the parasite. Experimentally, PSG exacerbates cutaneous and visceral leishmaniasis and can promote the chronicity of Leishmania infection, even in mouse strains normally capable of controlling leishmaniasis. The underlying mechanism of PSG's action is a major focus of our ongoing work. This review aims to synthesize what is known about the role and action of PSG and its constituent proteophosphoglycans, for parasite colonization of the sand fly, transmission, and mammalian infection. Lastly, we discuss potential exploitation of this important vector-transmitted product and future avenues of research.

Keywords: Leishmania, sand fly, promastigote secretory gel, saliva, proteophosphoglycan, transmission, macrophage, wound healing

\section{INTRODUCTION}

Leishmaniasis is a significant neglected tropical disease placing 350 million people in 88 countries Worldwide at risk of infection (WHO, 2010). It is caused by protozoa of the genus Leishmania, which require a female phlebotomine sand fly for transmission. Depending on the species of parasite and the host immune response leishmaniasis can range from self-limiting cutaneous lesions through to life-threatening infections of the liver and spleen if not detected and treated early enough.

To be transmitted by a sand fly the Leishmania must overcome a number of challenges within the sand fly gut and complete up to four transformations to the mammal infective stage, the metacyclic promastigote (Sacks and Kamhawi, 2001 and references therein). However, the majority of Leishmania's interaction with its vector at the molecular level still remains unknown. A common feature of Leishmania-infected sand flies is the presence of a mass of parasites embedded within a gel-like material (Stierhof et al., 1999). The origin of the gel was unknown until relatively recently, when it was demonstrated to derive from the parasite, now termed the promastigote secretory gel (PSG; Rogers et al., 2002). PSG is comprised largely of Leishmania proteophosphoglycans (PPGs). It has been proposed that the PSG improves the efficiency of Leishmania transmission by blocking the lumen of the insect's anterior midgut and stomodeal valve, resulting in a regurgitation of metacyclic promastigotes during an attempted bloodmeal (Stierhof et al., 1999). We have elaborated on this model and have shown that Leishmania PPGs in the form of PSG can manipulate the bloodfeeding behavior of its vector and the immune system of the mammalian host to promote Leishmania transmission and infection. This adds PPGs/PSG to the list of known components of Leishmania transmission, accompanying parasites and vector's saliva into the skin (Figure 1).

\section{LEISHMANIA PROTEOPHOSPHOGLYCANS AND THE PROMASTIGOTE SECRETORY GEL}

Leishmania synthesize abundant phosphoglycan (PG)-containing molecules made up of [Gal-Man-PO(4)] repeating units, including the surface lipophosphoglycan (LPG), and the surface and secreted PPGs (Figure 2). To date around 70 species of sand fly have been incriminated as vectors of leishmaniasis, of which, 30 have convincing evidence (Lane, 1993; Bates, 2007). In a significant number of these vectorial combinations a noticeable feature of heavily infected sand flies is the presence of the blockage in the anterior midgut formed by a mass of parasites embedded in PSG (Table 1); including a Leishmania species isolated from day biting midges, the causative agent of cutaneous leishmaniasis in red kangaroos (Dougall et al., 2011). Scanning electron microscopy of Phlebotomus papatasi and Lutzomyia longipalpis midguts infected with Leishmania major and L. mexicana, respectively, found a dense matrix of filaments which surrounded the parasites (Stierhof et al., 1999). These networks were identified as filamentous proteophosphoglycan (fPPG), the largest molecule secreted by Leishmania (3-6 nm diameter and up to $6 \mu \mathrm{m}$ length) and is biochemically indistinguishable from PPPG secreted by parasites in culture. 
In culture Leishmania tend to form aggregates. Electron microscopy of these clumps of cells revealed a fibrous material in the center; extruded from their flagellar pockets (Stierhof et al., 1994). These fibers have been purified and extensively characterized by Ilg and colleagues. Filamentous PPG appears to be made by all species of Leishmania since a large variety of New and Old World Leishmania species (L. mexicana, several strains of L. major, L. amazonensis, L. braziliensis, L. aethiopica, L. infantum, and $L$. donovani) have been shown to secrete this material in culture (Ilg et al., 1994, 1996; Stierhof et al., 1994, 1999). It is comprised predominantly of LPG-like phosphoglycans attached to a serine-rich protein backbone such that every second amino acid bears a PG molecule. Glycosylation of fPPG accounts for $~ 75 \%$ of its total molecular mass (Ilg, 2000). The PG molecules are formed of three variably substituted phosphodisaccharides that terminate with a neutral cap structure. It is this extensive phosphoglycosylation which inhibits the formation of secondary structures and gives fPPG its characteristic thread-like appearance. Leptomonad promastigotes are the main producers of fPPG in sand flies (Rogers et al., 2002). Filamentous PPG can be detected in L. mexicana or

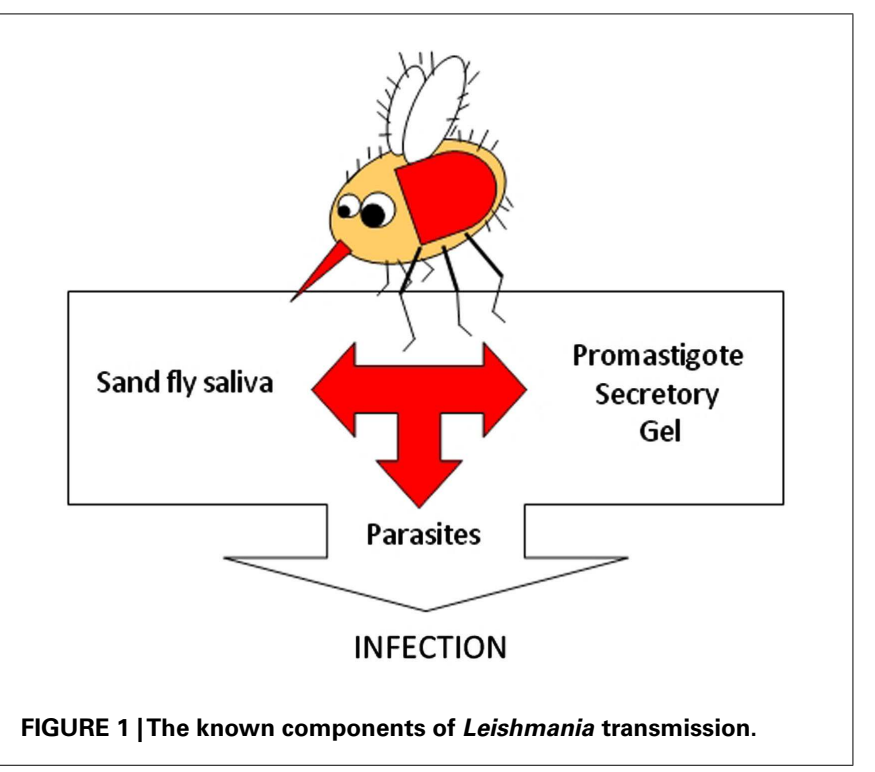

L. infantum-infected Lu. longipalpis guts from day $2 / 3$ onward, with a significant peak in production from days 5-7 post infection (Rogers et al., 2002; Gossage et al., 2003; Rogers and Bates, 2007). This corresponds precisely with the peak appearance of leptomonad promastigotes. These forms are derived from nectomonad promastigotes which migrate to the anterior thoracic midgut after bloodmeal digestion and defecation. It is here that leptomonads re-initiate cell division and multiply vigorously in the gut lumen achieving densities of $10^{10}-10^{11} / \mathrm{ml}$ (Rogers et al., 2002; Gossage et al., 2003). Within the confines of this part of the sand fly gut $(\sim 10 \mathrm{nl})$ fPPG accumulates and condenses into a gel-like mass, the PSG (Figure 3). Similarly, fPPG purified from culture supernatants forms a gel above 5-10 mg/ml (Ilg et al., 1996; Stierhof et al., 1999). The concentration of fPPG from a single $L$. mexicana-Lu. longipalpis infection is conservatively estimated at $1 \mathrm{~g} / \mathrm{ml}$. During the production of the PSG the majority of leptomonads enter metacyclogenesis and differentiate into infective metacyclic promastigotes (Rogers et al., 2002). The cues which initiate PSG production remain unknown but metacyclogenesis and PSG production in sand flies seem inextricably linked.

Herein I will refer to PSG, fPPG, and PPG interchangeably.

\section{PPGs ENABLE SAND FLY COLONIZATION}

Within the sand fly, Leishmania need to achieve numerous tasks in order to have a chance at transmission. They must multiply, negotiate their way to sand fly's anterior midgut and mouthparts and differentiate into the mammal infective form, the metacyclic promastigote. Along the way Leishmania encounter a number of barriers to successfully colonize the sand fly. Leishmania need to: (i) survive hydrolytic attack from the sand flies' digestive enzymes, (ii) negotiate their way out of the chitinous peritrophic membrane that surrounds the bloodmeal, (iii) resist being expelled when the sand fly defecate their digested bloodmeal, and (iv) survive the sand fly's immune response (lectins and antibacterial peptides). There are a number of PPGs expressed by promastigotes in the sand fly host (reviewed by Ilg, 2000) and we are just beginning to realize their diverse roles for the Leishmania-sand fly interaction. Observations made from sand fly infections using mutant L. major deficient in LPG (lpg1) or deficient for all surface and secreted PGs (lpg2) have pointed toward a role for secreted PPGs for the early

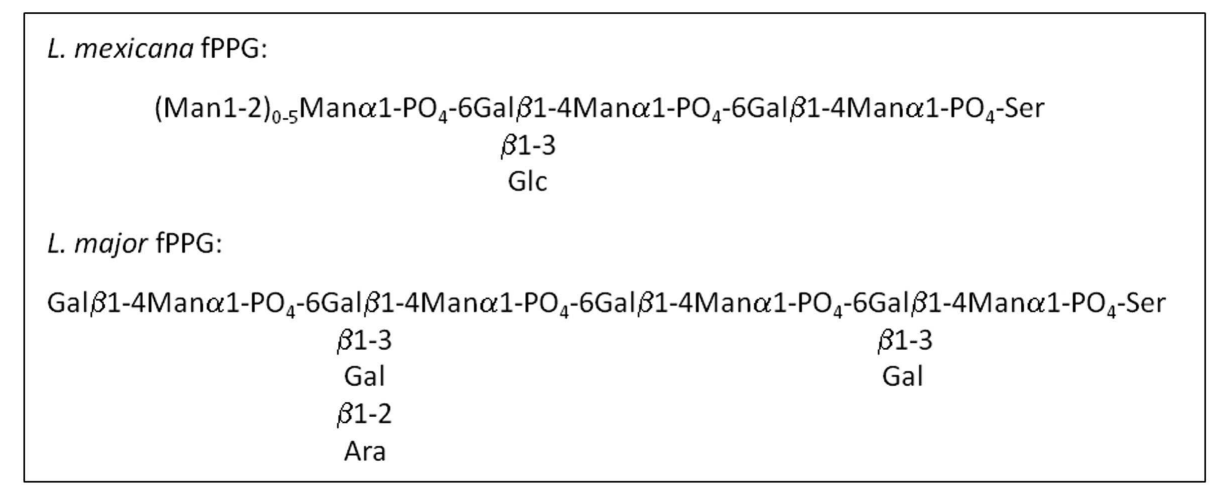

FIGURE 2 | Structure of Leishmania filamentous proteophosphoglycan. 


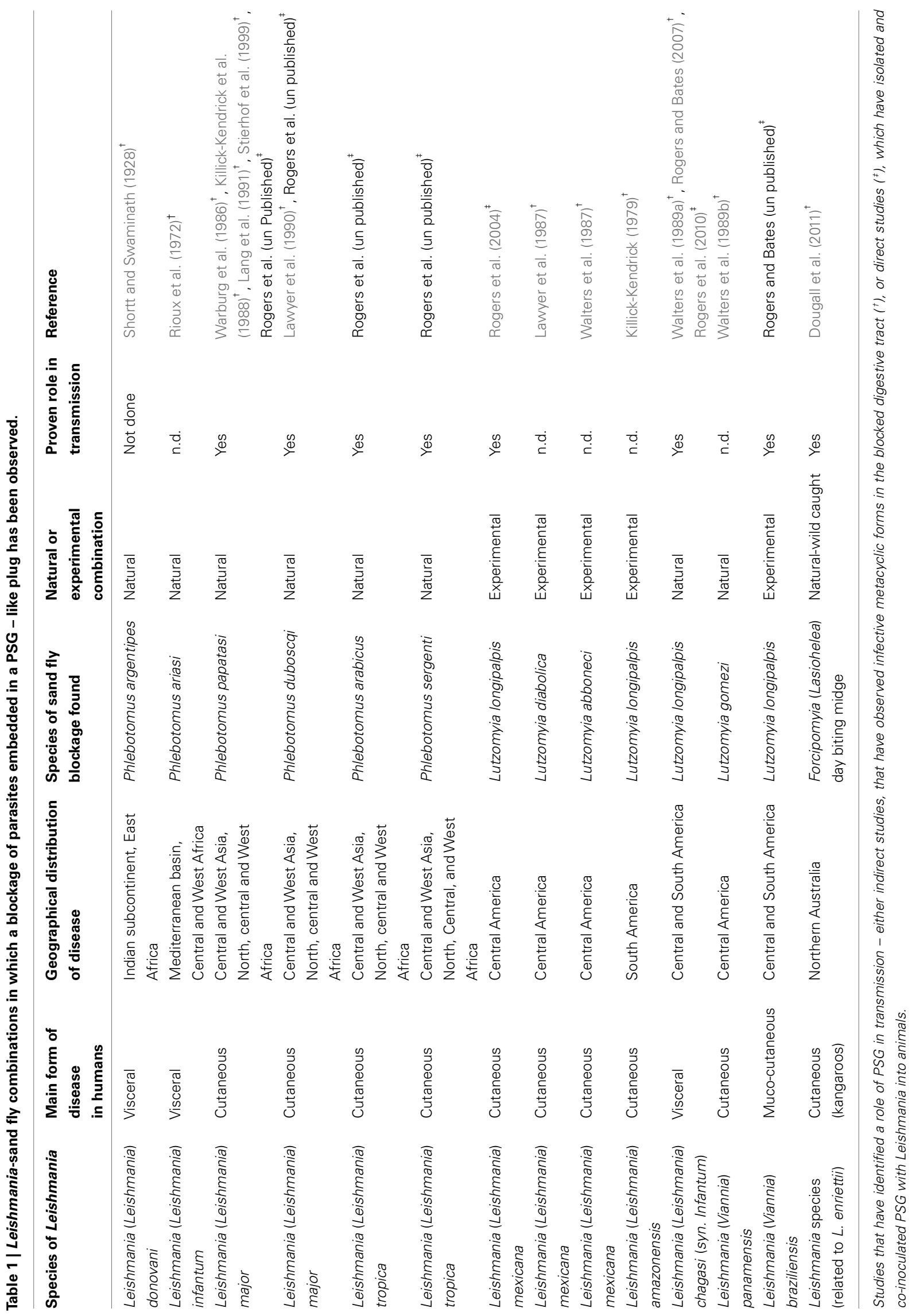




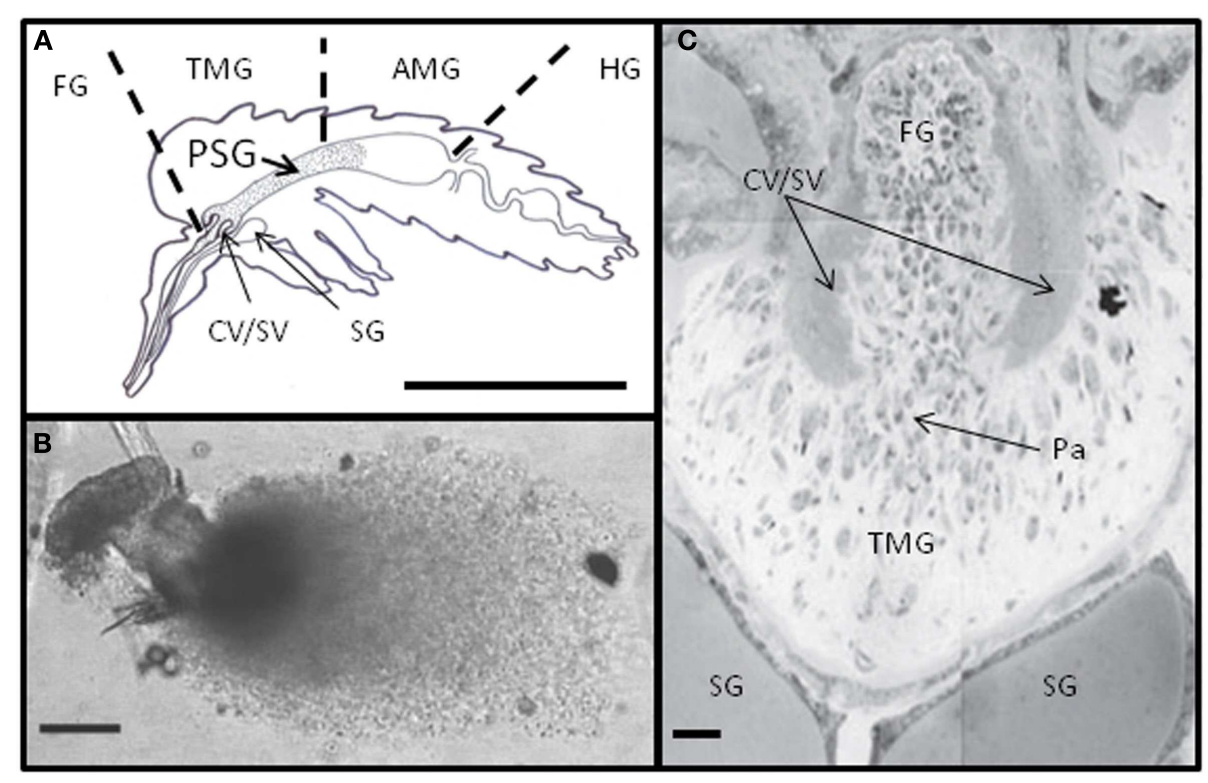

FIGURE 3 |The PSG plug. (A) The typical position of Leishmania PSG in the gut of heavily infected sand flies (FG, foregut; TMG, thoracic midgut; AMG, abdominal midgut; $\mathrm{HG}$, hindgut; CV/SV, cardiac or stomodeal valve; SG, salivary gland; scale bar: $1 \mathrm{~mm}$ ). (B) Freshly dissected PSG from $L$. mexicana-infected Lu. longipalpis (scale bar: $100 \mu \mathrm{m}$ ). (C) Sagittal section through the anterior thoracic midgut of a heavy L. mexicana-Lu. Iongipalpis infection, showing numerous attached and unattached parasites $(\mathrm{Pa})$ and occlusion to the stomodeal valve (Scale bar: $10 \mu \mathrm{m}$ ). survival of promastigotes during bloodmeal digestion (Sacks et al., 2000; Svárovská et al., 2010). In vitro experiments with promastigotes incubated with sand fly midgut lysates prepared at various times post bloodmeal showed that secreted PPGs confer protection from enzyme mediated attack (Secundino et al., 2010). In an elegant series of experiments, Secundino and colleagues showed that purified PPG, and not LPG, could passively adhere to the surface of $l p g 2$ parasites to confer this protection. These studies tell us number of things - firstly, they show that PPG has the potential to stick to the surface of promastigotes, which may be relevant during the initial stages of mammalian infection; and, secondly, PPGs have multiple roles for the parasite inside the sand fly. In the future it will be interesting to investigate the kinetics of PPG production and its precise interaction with the sand fly. With an expanding knowledge of sand fly genomics, coupled with the development of RNAi as a new tool for interrogating sand fly gene function (Sant'anna et al., 2009; Coutinho-Abreu et al., 2010), studies of this kind will greatly improve our understanding of sand flies as vectors of leishmaniasis.

\section{PPGs ALTER SAND FLY FEEDING BEHAVIOR}

Sand flies belong to a large group of arthropod vectors known as pool feeders, which include tsetse flies, black flies, midges, ticks, and fleas. Sand flies saw into the skin of the mammalian host with their barbed mouthparts, lacerating dermal capillaries to form a pool of blood. This is in direct contrast to other vectors such as mosquitoes which cannulate individual blood vessels, causing less damage to the skin. Whilst biting, sand flies continuously secrete their saliva into the wound to keep the blood liquid. They then suck the blood from the pool into the pharyngeal chamber before it is pushed through the cardiac or stomodeal valve into the midgut.
Here it is rapidly encapsulated in a peritrophic matrix, allowing the process of digestion to begin. One of the clearest roles for PPG, in the form of PSG, in the sand fly vector is its ability to modify its bloodfeeding behavior for parasite transmission. Since the discovery of sand flies as vectors of leishmaniasis various workers have observed distinct changes to the behavior of infected sand flies. Notably, infected sand flies probe more frequently, take longer to feed, and are more likely to take incomplete meals compared to their uninfected siblings (Shortt et al., 1931; Killick-Kendrick et al., 1977; Beach et al., 1985; Rogers et al., 2002; Rogers and Bates, 2007; Maia et al., 2011). Although the observation that infected sand flies can experience difficulty with feeding is not new, the connection between this behavior and the likelihood of increased parasite transmission was not made until the late 1970s when Killick-Kendrick et al. (1977) re-analyzed the data of Chung et al. (1951). They showed that Phlebotomus chinensis were more likely to transmit $L$. donovani to hamsters when flies probed and took no blood compared to those infected flies that took a bloodmeal. This demonstrated that Leishmania could manipulate the feeding ability of the sand fly to promote its own transmission success.

There are a large number of studies that show that parasites can manipulate the behavior of their arthropod vectors, but rarely is a "manipulator molecule" identified (Rossignol et al., 1984; Hurd, 2003). In 2002 a clear relationship between the intensity of Leishmania infection and the feeding ability of sand flies was established (Rogers et al., 2002). It was found that the majority of heavily infected flies (87\%) were only capable of taking a partial bloodmeal and this was associated with accumulation of PSG, resulting in a threefold increase in the volume of the anterior midgut and significant expansion of the stomodeal valve. In 
its quest for transmission, Leishmania can also cause pathology to the chitin-lined stomodeal valve by attaching to it, through modification of their flagellum and the secretion of chitinase (Schlein et al., 1992; Volf et al., 2004; Rogers et al., 2008). The combination of these two events results in the blockage of the anterior midgut with a plug of Leishmania promastigotes and their accompanying gel, which distends and permanently holds open the eroded valve. This is hypothesized to adapt the sand fly for efficient transmission by promoting the reflux of parasites during blood feeding and the deposition of large numbers of infective forms - the "blocked fly hypothesis" (Shortt and Swaminath, 1928; Figures 3 and 4).

When considering the behavioral manipulation of vectors by parasites it is important to bear in mind that host contact and blood feeding do not come without risks and present a considerable danger to both vector and parasites alike when the host defends itself (Klowden and Lea, 1979; Davies, 1990; Anderson et al., 2000), so it is possible that these effects alone are not necessarily selectively advantageous. Therefore, the timing of vector feeding with respect to parasite development is a crucial, since successful transmission of parasites requires their vectors to survive long enough for the parasites to complete their development to an infective stage (the extrinsic incubation period; Anderson et al., 1999, 2000; Hurd, 2003; Thomas et al., 2005). In a seminal experiment using the rodent malaria-mosquito model of Plasmodium yoelii and Anopheles stephensi, Anderson et al. (1999) observed the bloodfeeding of infected mosquitoes to be more persistent once the extrinsic incubation period was completed. In such a scenario, the timing of transmission opportunities is critical in order to reduce the risk of premature death of the infected vector and promote its survival long enough to complete the parasite's extrinsic incubation period. Feeding persistence is the repetition of feeding attempts when prevented from feeding, i.e., when a host defends itself. The biting persistence of a vector to resume feeding after interruption is considered an important parameter of vectorial capacity (Koella et al., 1998).

In a comprehensive study of $L u$. longipalpis infected with $L$. infantum and L. mexicana (natural and experimental combinations, respectively) it was found that interrupted flies were more persistent in their bloodfeeding (Rogers and Bates, 2007). This increased in parallel with the development of the parasites, the number of transmission stages (metacyclic promastigotes), and the accumulation of PPG - the main component of PSG. As a consequence, flies with the highest number of metacyclic promastigotes were also found to be more likely to initiate a second feed on naive hosts. The lesions generated from the bites of individual $L$. mexicana-Lu. longipalpis demonstrated that this form of behavioral manipulation directly resulted in enhanced parasite transmission. Importantly, these changes to the vector's behavior were only seen when the flies were interrupted and infected flies presented to anesthetized animals usually bit once and fed until they were engorged. This study confirmed that influencing a sand fly's biting persistence is a developmental strategy for Leishmania and a form of adaptive manipulation because: (i) it relies on the successful establishment and development of the parasite within the sand fly, requiring many intrinsic barriers to be overcome, (ii) the behavior is only exhibited when the parasite is ready for transmission, (iii) the fPPG gel appears to have arisen independently in other Leishmania-sand fly combinations, and (iv) the manipulation directly increases the fitness of the parasite through enhanced transmission.

Previously, it was suggested that the attachment of Leishmania parasites in contact with the foregut might interfere with the function of mechanoreceptors that detect blood flow, and this might explain the reduced ability of flies to take a blood meal (Jenni et al.,
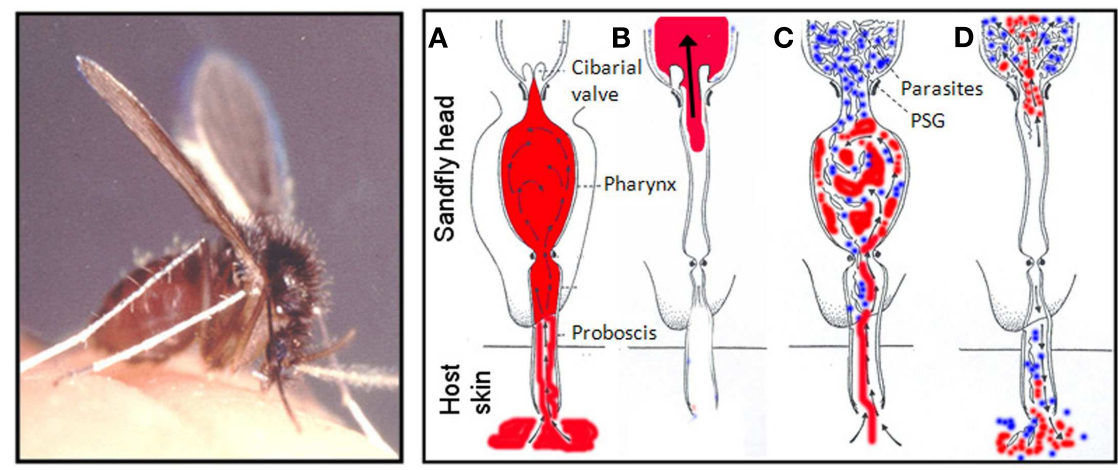

FIGURE 4 | The blocked fly hypothesis and regurgitative model of Leishmania transmission. Female sand flies (Lutzomyia longipalpis is shown, scale bar: $1 \mathrm{~mm}$ ) feed from a pools of blood (in red) in the skin. (A-D) Represent cross-sections through the sand fly head as it feeds and show how PSG promotes parasite regurgitation: During feeding, uninfected sand flies $(\mathbf{A}, \mathbf{B})$ draw blood into the pharynx which is diverted into the midgut through the one-way cibarial or stomodeal valve where it is digested. In heavily infected sand flies (C,D) Leishmania parasites attach to the valve and multiply in the anterior midgut. At the same time the parasites secrete filamentous proteophosphoglycan (fPPG) which condenses to form the promastigote secretory gel (PSG - in blue) obstructing the midgut and pharynx. Gel blockages have been observed in a large number of Leishmania-sand fly combinations described to date and characterized in both experimental (L. mexicana in Lu. longipalpis) and natural (L. major in P. papatasi, L. infantum in Lu. longipalpis) Leishmania-sand fly combinations. The PSG blockage forces open the cibarial valve allowing parasites and gel to reach the pharynx and foregut, allowing blood to mix with PSG when it is taken into the pharynx (C). Since PSG is highly soluble, when blood is eventually drawn through the parasite-gel obstruction a proportion of midgut parasites and PSG are regurgitated by backflow into the skin of the vertebrate host (D). Sand fly photo is courtesy of Prof. R.W. Ashford and the diagram is after Schlein et al. (1992). 
1980; Molyneux and Jefferies, 1986). However, in view of these results it was proposed that the functioning of these mechanoreceptors is impaired by fPPG, which plays the role of manipulator molecule. This in turn may promote the hunger state and the persistence of the fly, or alternatively, increase the threshold blood volume at which blood-seeking behavior is inhibited. However, what we may be seeing is just the tip of the ice-berg; where PSG may affect many different neuronal, gustatory, endocrine, or even odor-sensing pathways to influence bloodfeeding.

One of the next challenges is to investigate whether this manipulation is relevant for transmission in the field. It has been observed for a variety of different Leishmania species in different parts of the World that cases of leishmaniasis or Leishmania seropositivity often cluster at the village and sometimes household level (Ashford et al., 1992; Evans et al., 1992; Schenkel et al., 2006; Bousslimi et al., 2010). The risk of Leishmaniasis is commonly associated with crowded households and multiple lesions for particular Leishmania species are not uncommon (Ashford et al., 1992; Ampuero et al., 2006; Bousslimi et al., 2010; Singh et al., 2010). Tentatively, these pieces of evidence suggest the behavioral manipulation of sand flies in action. Recently, a 3 year community wide study in India and Nepal concluded that insecticide impregnated bed nets do not significantly protect against $P$. argentipes bites (Gidwani et al., 2011) and visceral leishmaniasis (Picado et al., 2010). This was surprising because it was assumed that $P$. argentipes, an indoor, night-biting vector, was an ideal candidate for such an intervention strategy. This highlights the urgent need to reexamine and re-evaluate our knowledge of this, and other, important Leishmania vectors; particularly their behavior when infected.

\section{PPGs AND THE BLOCKED FLY HYPOTHESIS OF LEISHMANIA TRANSMISSION}

To gain insight into the mechanisms that govern Leishmania infection in the wild and replicate natural infection more closely in the lab it is important to understand the context of the infectious bite, i.e., the site and dose of parasites and the role of molecules egested from the infected vectors. The site and dose of Leishmania transmission by sand flies is likely to affect the evolution of the disease (Bretscher et al., 1992; Doherty and Coffman, 1996; Belkaid et al., 1998). In the vast majority of experimental studies little attention is given to the kinetics of Leishmania infection by sand fly bite. Models of cutaneous leishmaniasis mice are typically initiated with large doses of parasites $\left(10^{5}-10^{7}\right)$, derived from in vitro culture and delivered intradermally or subcutaneously by needle to the skin (Kimblin et al., 2008). For visceral models of leishmaniasis the situation is worse, where skin is rarely used as the site of inoculation. Rather, the sand fly is bypassed entirely and animals are often infected intravenously or intracardially, with large doses of amastigotes or axenic promastigotes (Maia et al., 2011). Although Leishmania are exclusively transmitted by sand flies, studies of infection from the bites of infected flies are very rare. Nevertheless, on the occasions they have been used (Kamhawi et al., 2000; Rogers et al., 2004, 2006, 2008; Rogers and Bates, 2007; Kimblin et al., 2008; Maia et al., 2011) they have proved very instructive.

Different approaches have been employed to determine the dose of Leishmania delivered by sand flies, including: (i) direct counting of egested parasites following force-feeding with microcapillaries (Warburg and Schlein, 1986), or following (chick skin) membrane feeding (Rogers et al., 2004, 2010), or (ii) indirectly, through quantitation of Leishmania transcripts from bitten mouse ears by real time PCR (qPCR; Kimblin et al., 2008; Maia et al., 2011). Each have their advantages and disadvantages but ultimately information from the number of parasites in bitten skin using GPCR - a technique that, when optimized, can detect as few as 10 egested parasites, has provided the most physiologically relevant data to date. Moreover, these types of study have the power to resolve the variability of individual fly transmission and identify important features of the infection that may determine of successful transmission. In the L. major - P. duboscqi model, it was demonstrated that the number of promastigotes inoculated by individual sand flies ranged between 10 and 100,000 Leishmania (Kimblin et al., 2008). Within this range a bimodal distribution of parasite delivery was observed, where $\sim 75 \%$ of transmitting flies delivered fewer than 600 parasites and the rest delivered significantly higher doses of more than 1,000 parasites. In another study that investigated the numbers of $L$. infantum from single P. perniciosus and Lu. longipalpis strikingly similar results were found (Maia et al., 2011). The average dose was 500, with the majority of transmitting females inoculating less than 600 parasites. In this instance there was a significant correlation between the prefeeding infection intensity and the transmitted dose. From the L. major-P. duboscqi study, high dose transmission also correlated with large midgut infections of over 30,000 promastigotes. Because of the sensitivity of qPCR and the ability to track the infection outcome of small groups, or even single infected flies it is possible to interrogate the data from these experiments to obtain infection parameters in the fly which successfully predict transmission. Meta-analysis of L. major transmission by groups of four to five infected $P$. duboscqi allowed the authors to show that flies with $\sim 70 \%+$ metacyclics in their gut were predictive of successful transmission to the majority $(\geq 70 \%)$ of bitten animals (Stamper et al., 2011). It was concluded that the rare but high dose transmissions probably result from a regurgitation of parasites from the PSG-blocked midgut. Further corroborating the blocked fly hypothesis, both transmission studies of L. major and L. infantum found a strong correlation between the midgut infection intensity and the ability of the fly to engorge satisfactorily on blood.

As PSG production relies upon metacyclogenesis we hypothesized that the quantity of egested PSG would also correlate with the size of the sand fly infection. To test this we used capillary feeding to assess the transmission of L. mexicana from Lu. longipalpis, an experimental combination which generates generous amounts of PSG (up to $1 \mu \mathrm{g} / \mathrm{fly}$ ) and is highly transmissible to mice (typically $\geq 85 \%$ single infected bites lead to cutaneous lesions; Rogers et al., 2006, 2008; Rogers and Bates, 2007). Capillary feeding gave finer control over individual flies, allowing us to standardize the feeding process. By analyzing the egestate of each fly by semi-quantitative immunodot-blot we could group them into those that regurgitated high (average \pm SD: $0.03 \pm 0.06 \mu \mathrm{g}$ ) and low (average \pm SD: $0.0004 \pm 0.00016 \mu \mathrm{g}$ ) amounts of PSG (Rogers et al., 2009). This correlated significantly with the intensity of their midgut infections and revealed that sand flies egesting high amounts of PSG tended to transmit more parasites. These results reinforce the idea 
that parasite fPPG can greatly influence the number of transmitted parasites and the proportion of co-regurgitated gel. In this regard it will be worth addressing the role of PSG in determining the parasite dose and composition more closely, as it may prove to be a more accurate predictor of successful transmission and infection. Ultimately, testing the importance of PSG in transmission would benefit enormously from a fPPG-deficient parasite line. The main reason that we don't have PPPG null mutant is that the gene is too large for knocking out ( $\sim 50 \mathrm{~kb})$; but it may be amenable to genedisruption. Currently the closest we have come is the generation of lpg2 null parasites, which lack all phosphoglycans - surface bound and secreted. Unfortunately, this parasite does not survive past the bloodmeal phase of development as it is expelled by the sand fly during defecation (Sacks et al., 2000). I rather suspect that the same would happen to a PPG null infection, as it appears that the gel anchors the infection in the anterior midgut.

Until recently sand fly transmission was regarded as a single fly activity. A recent study using Lu. longipalpis has challenged this concept when it was observed that sand flies tended to feed in aggregates (Tripet et al., 2009). Flies that did so fed more efficiently, obtaining more blood in a faster amount of time compared to single feeding flies. The authors also noted that aggregated flies used less of their saliva for feeding and speculated that by sharing resources this may represent a cooperative behavior amongst sand flies which provides them with numerous fitness gains. Interestingly, the benefit of aggregated feeding was most pronounced when the flies were offered saliva-immunized mice as a bloodmeal. In contrast, flies fed singly on immunized mice was detrimental to the volume of blood taken and the number of eggs generated (Milleron et al., 2004). In this scenario and flies that aggregate may be taking advantage of an increased local blood flow to the bite site caused in part by a delayed type hypersensitivity reaction to the vector saliva (Belkaid et al., 2000). It would be interesting to test whether this behavior is affected at different points during the sand fly infection and the accumulation of PSG, or if transmission would benefit from the presence of uninfected flies in an aggregate?

I often get asked by colleagues what is the dose of Leishmania from a sand fly bite? For convenience I tell them the average number of parasites delivered per bite. For L. mexicana this is currently 1,000; for L. infantum it is 500 and for L. major it is between 500 and 1,000 . It is tempting to satisfy ourselves with this reductionist approach to transmission, however, as discussed above Leishmania transmission can be highly variable and influenced directly by the parasite itself. So perhaps it is more pertinent to think in terms of how many parasites is a fly capable of delivering, or likely to deliver during feeding? Undoubtedly, information like this will eventually have to take into account the development of the parasite, and the secretion of fPPG, which can influence the feeding behavior of the sand fly and the parasite dose.

\section{PPGs ENHANCE LEISHMANIA INFECTION OF THE MAMMALIAN HOST}

Needle injection of Leishmania metacyclic promastigotes with sand fly saliva does not faithfully reproduce the effects of infected sand fly bite, and discrepancies in epidermal cytokine responses (in particular, the Th2-driving cytokines IL-4 and IL-5) have been reported (Kamhawi et al., 2000). This indicates that in addition to saliva other sand fly factors affect immune responses to Leishmania. From our work there appeared to be a convincing role for PSG in the blocked fly and regurgitative mode of transmission. In 2004 we took this one step further and asked whether the regurgitated PSG could actively influence the Leishmania infection in the mammalian host? From membrane feeding experiments, using groups of L. mexicana-infected Lu. longipalpis, we found that PSG was actively egested by infected flies (Rogers et al., 2004). Coinfection experiments in mice using the physiologically relevant dose of 1,000 metacyclic promastigotes we showed conclusively that PSG could potently exacerbate cutaneous $L$. mexicana infection (Rogers et al., 2004) and enhance its transmission back to flies (unpublished results). This effect was observed both in terms of parasite lesion evolution (lesions were faster to appear than the controls and grew larger) and final amastigote burden. Strikingly, this effect was evident in both Leishmania-resistant (CBA/Ca) and Leishmania-susceptible (BALB/c) strains of mice. Furthermore, in healer $\mathrm{CBA} / \mathrm{Ca}$ mice we found PSG to enhance the chronicity of $L$. mexicana infection. Using this infection model we have since found that PSG can benefit L. mexicana over a wide range of doses $(10-10,000)$, hinting that it is important to the parasite irrespective of the bloodfeeding attempt - i.e., it may be able to exacerbate infections from those flies that just probe or from those that feed for longer and take a full bloodmeal (Rogers et al., 2009). The component of PSG responsible for promoting leishmaniasis was identified as glycans donated from fPPG, the scaffold of the gel (Rogers et al., 2004). Curiously, in combination with the saliva from the vector, another important component of transmission, the disease enhancing properties of PSG is reduced but the net result is still beneficial to the parasite. Recently we have established a role for PSG for infection with a number of other Leishmania species (Table 1), including L. infantum, the agent of zoonotic visceral leishmaniasis in South America (Rogers et al., 2010). For this parasite it was interesting to observe that the combination of PSG and Lu. longipalpis saliva was additive in their ability to PSG enhanced both the skin and visceral phase of infection depending on dose. In addition, we have observed a role for PSG for L. major, L. tropica, and L. braziliensis infections (unpublished results), demonstrating that it is likely to be important for a wide range of Leishmania species, from natural or experimental parasite-vector combinations.

During the first few days of infection the parasite is most vulnerable to the potent innate immune responses of the host to the sand fly bite. This is exaggerated for sand flies since they inflict more damage to the skin - by lacerating the capillary loops of the upper dermis with their serrated proboscis to feed from a pool of blood. This means that the PSG and vector saliva operate in a wound environment. In this context, we found that PSG was able to strongly influence neutrophil and macrophage recruitment, and worked in alliance with saliva (Rogers et al., 2009). This effect was and was observable by $4 \mathrm{~h}$ in mouse dermal air pouches. Since neutrophils and macrophages host Leishmania (Sacks and Kamhawi, 2001; Peters et al., 2008) the sand fly bite, saliva, and parasite PSG work synergistically to provide more potential host cells to the site of infection.

Next, we found that the presence of PSG with macrophages, in vitro or in vivo, benefited infection, irrespective of the activation 
status of the cell. Potentially, this allows Leishmania to survive in hostile environments such as inflamed skin exposed to the bites of the vector or immunized with its saliva. It appears that PSG reduces the efficiency of parasite elimination in inflammatory macrophages (M1 or classically activated macrophages - CAM $\Phi$ ). In these cells L-arginine is catabolized by nitric oxide synthase 2 , also known as inducible nitric oxide synthase, (NOS2/iNOS) to generate nitric oxide (NO), which mediates one of the most potent killing mechanisms of intracellular Leishmania parasites (Bogdan, 2001). Nitric oxide synthase 2 is expressed in vivo in the early phase of infection (Stenger et al., 1996) when macrophages respond to innate recognition pathways and the activation of toll like receptors (TLRs; Kropf et al., 2004). It has been shown that NOS2 expression can be suppressed in vitro by the saliva of sand flies, including Lu. longipalpis (Hall and Titus, 1995). In our hands, Lu. longipalpis saliva did not influence NO generation or the course of L. mexicana infection in vitro. Furthermore, L. mexicana PSG, either alone or in combination with sand fly saliva, did not influence NO production directly. Instead, we found that PSG enhanced the alternative activation of macrophages, by increasing their arginase- 1 expression and activity (Rogers et al., 2009). Therefore, PSG may compete with NOS2 for L-arginine, indirectly reducing NO production.

Leishmania have developed numerous strategies to prevent immune elimination. One such mechanism targets the L-arginine metabolism of macrophages (Figure 5). Macrophages can either kill or host intracellular amastigote forms of Leishmania depending on the balance of two inducible enzymes, nitric oxide synthase 2 (NOS2/iNOS; Wei et al., 1995) and arginase-1 (Kropf et al., 2005) which share the same substrate, L-arginine and are controlled by the environmental balance of Th1/pro-inflammatory (e.g., IFN $\gamma$, $\mathrm{TNF} \alpha$ ) and Th2/anti-inflammatory (e.g., IL-4, IL-10, IL-13, IL21) cytokines (Figure 5A). Increased arginase is associated with resistance to worm infections, allergic conditions such as asthma and Th2 induced pathologies (Tominaga, 1989; Kropf et al., 2004; Schleicher et al., 2007; Whitaker et al., 2008). Th1 cytokines induce classical activation of macrophages (CAM $\Phi)$, upregulating iNOS which catabolizes L-arginine into the Leishmania-toxic metabolite nitric oxide (NO). Th2 cytokines alternatively activate macrophages (AAM $\Phi)$ and induce arginase-1 which hydrolyzes $\mathrm{L}$-arginine into urea and L-ornithine; the latter being the first building block for the synthesis of polyamines. Polyamines are small cationic molecules required for cell growth, wound healing, homeostasis, and are essential for intra-macrophage growth of Leishmania (Kropf et al., 2005).

Since PSG can also promote the chronicity of cutaneous leishmaniasis in "healer" strains of mice there may be a potent effect on the adaptive immune response to these parasites. In humans it is generally accepted that immunosuppression is a common feature of non-healing cutaneous leishmaniasis (Bomfim et al., 1996) and visceral leishmaniasis (Ho et al., 1983; Sacks et al., 1987; Nylen and Sacks, 2007). Peripheral blood mononuclear cells from these patients typically have an impaired ability to proliferate, produce IFN $\gamma$ or are anergic to antigen restimulation (Ho et al., 1983; Barral et al., 1986; Sacks et al., 1987; Nylen and Sacks, 2007). Similarly, studies of mouse T cell function recovered ex vivo from the site of cutaneous leishmaniasis show similar immune hyporesponsiveness (Rodriguez et al., 2002, 2003, 2004, 2007; Bronte and Zanovello, 2005; Munder et al., 2005, 2006; Kropf et al., 2007). From murine models of cutaneous leishmaniasis it is now becoming clear that Leishmania additionally benefit from a high accumulation of $\operatorname{AAM} \Phi$ in cutaneous lesions via their high demand for, and local depletion of, L-arginine in the microenvironment (Figure 5B). In contrast to macrophages, $\mathrm{T}$ lymphocytes are acutely sensitive to L-arginine starvation (Choi et al., 2009); rapidly becoming hyporesponsive to antigen stimulation and exhibiting impaired proliferation, cytokine secretion,

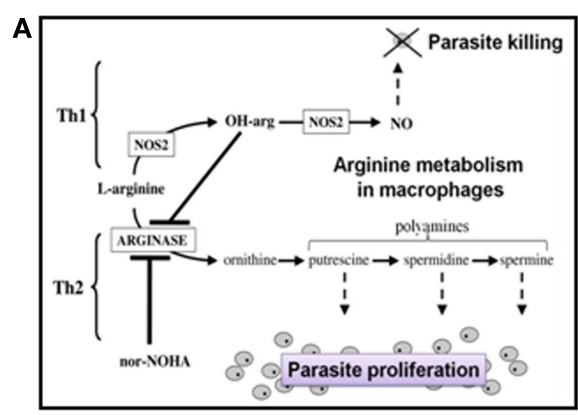

FIGURE 5 | Arginine and Leishmania survival. (A) L-arginine can have a direct influence on Leishmania intra-macrophage survival. L-arginine can influence the macrophage's ability to host or kill Leishmania, depending on the cytokine milieu they are exposed to. In the classically activated state, macrophages can metabolize L-arginine into nitric oxide (NO) when they perceive Th1 cytokines or pro-inflammatory mediators. Nitric oxide is potently toxic to Leishmania amastigotes. In direct contrast, alternatively activated macrophages can catabolise L-arginine into polyamines when they experience Th2 cytokines/anti-inflammatory mediators. Polyamines are an essential food source for intracellular amastigotes. Promastigote secretory gel appears to promote the alternative activation of macrophages, corrupting them into "superfeeders" for the parasites they

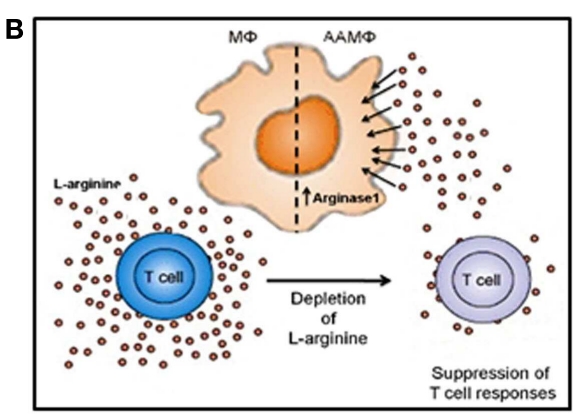

host (NOS2, nitric oxide synthase 2; $\mathrm{OH}$-arg, naturally occurring endogenous inhibitor of arginase; nor-NOHA, selective competitive arginase inhibitor). (B) L-arginine can also influence the adaptive immune response indirectly by affecting $T$ cell function. $T$ cell proliferation, $T$ cell receptor signaling, and cytokine secretion are acutely responsive to the levels of extracellular L-arginine. Within cutaneous Leishmania lesions of mice the accumulation of alternatively activated macrophages leads to the depletion of extracellular L-arginine. As a consequence, $T$ cell function is severely impaired, and the long-term survival of the parasites enhanced. A role for PSG in this model of immunopathology for leishmaniasis has yet to be determined but is speculated to occur. The figures are after Kropf et al. (2005) and Müller et al. (2009). 
$\mathrm{CD} 3 \zeta \mathrm{T}$ cell receptor chain expression, and T cell receptor signaling. For experimental L. major infection of BALB/c and CBA/Ca mice, by needle inoculation, it has been show that these two mechanisms contribute toward uncontrolled growth of parasites within the cutaneous lesion (Modolell et al., 2009; Munder et al., 2009). Specifically, uncontrolled replication of $L$. major in BALB/c mice correlated with abnormally high levels of arginase activity, a reduction in local L-arginine levels and a local suppression of CD4+ $\mathrm{T}$ cell responses within the lesion and not at the draining lymph node. Along with questions regarding the quantity and persistence of PSG in skin, how relevant this model is for natural infection by sand fly bite still remains to be addressed. Moreover, in humans modulation of $\mathrm{L}$-arginine in the microenvironment is more likely to come from the action of neutrophils and not macrophages (Rotondo et al., 2011; Sippel et al., 2011). Arginase released by degranulating activated or dying neutrophils can bind to and sequester L-arginine, reducing its bioavailability (Müller et al., 2009 and references therein). Since we now know that neutrophils transiently host Leishmania until macrophages arrive (Peters et al., 2008), investigating the interaction between PSG and neutrophils may prove very revealing for the earliest stages of infection.

The other major component of Leishmania transmission is sand fly saliva. This is essential for efficient bloodfeeding for the sand fly by promoting blood flow to the bite site and by modulating the immune response to the bite. Not surprisingly therefore, these factors also play important roles in the establishment of Leishmania infection. Injection of $P$. papatasi salivary gland sonicates can induce a rapid expression of IL-4 from mouse epidermal cells and Lu. longipalpis saliva can induce IL-10 expression from mouse ear tissue and cultured macrophages (Mbow et al., 1998; Norsworthy et al., 2004; Monteiro et al., 2007). Both these cytokines synergize in the alternative activation of macrophages, the expression of arginase in macrophages and the promotion of parasite growth (Kropf et al., 2005). Despite this, saliva and PSG did not act additively on macrophage arginase activity or parasitism, reflecting previous infections in mice (Rogers et al., 2004). Recently, it has been shown that cytokine-dependent, STAT 6-dependent pathways as well as TLR-dependent, STAT 6 independent pathways can induce arginase-1 in macrophages depending on the type of infection (El Kasmi et al., 2008). Indeed, it has been shown that increased Leishmania survival in TLR4-deficient host cells correlates with enhanced arginase activity (Kropf et al., 2004). Furthermore, the disparity in the cytokine responses invoked by the injection of salivary gland sonicate with Leishmania (Belkaid et al., 1998) and infected sand fly bite (Kamhawi et al., 2000) may be due to the unaccounted presence of PSG in the latter; suggesting that PSG and sand fly saliva may indeed act via different pathways or cytokines.

It has been shown that resistance of mice to L. major infection was associated with high collagen deposition and a faster rate of wound healing, controlled in part by three leishmaniasis susceptibility loci mapped to chromosome 17 (Sakthianandeswaren et al., 2005). However, it has also been established experimentally in mice that L. amazonensis can readily metastasize to a fresh skin cut (Bertho et al., 1994) and clinical cases of new cutaneous Leishmania lesions following local trauma to the skin has been recorded (Wortmann et al., 2000 and references therein), therefore, our understanding of leishmaniasis and the wound response is less than complete. The influence of PSG strongly suggests that Leishmania can modulate the early wound healing process. Wound healing, however, is a highly complex and dynamic process involving many cell types, so for the future it would be important to dissect further the influence of PSG on the wound healing process itself. Collectively, these data suggest that Leishmania, through secretion of PSG, has evolved mechanisms to modulate both the wound healing process and the adaptive immune response to ensure its own survival and transmission.

\section{THE USE OF SAND FLIES IN LEISHMANIA RESEARCH}

We and others have shown that sand flies generate inocula and immune responses that are qualitatively very different from simply injecting parasites by needle. Throughout this review I have taken care to highlight the research involving natural and experimental Leishmania-sand fly combinations. In an ideal World every Leishmania research lab would have their own sand fly colony pertinent to the species of parasite they worked on; however, there are very good reasons why one may favor particular sand fly species over another. According to their vectorial capacity, sand flies can be broadly categorized into "restrictive vectors" - which sustain the development of only one Leishmania species (e.g., L. major in P. papatasi, L. tropica in P. sergenti) or "permissive vectors" - which can host a wide range of Leishmania species until maturity (e.g., Lu. Longipalpis, P. argentipes; Myskova et al., 2007). Understandably, many labs favor the use of permissive vectors, or a mixture of permissive and restrictive species.

When studying transmission and infection by fly bite, having the natural Leishmania-sand fly combination may have added benefit. For example, the morphology of that particular sand fly may influence the ability of the fly to bloodfeed or transmit, as dimensions in mouthparts or cibarial armature can be strikingly different. The microflora of the sand fly gut may also have an as yet undefined role to play in Leishmania colonization of their vector, or transmission and infection of the mammalian host itself. More directly however, is the composition or quantity of the sand fly saliva as this may have specific interactions with the parasite PSG and/or the host's skin that may influence the infection.

Rearing, maintaining, infecting, and manipulating sand flies is hard to do. It is time consuming and labor intensive, requiring considerable experience, expertise, and resources. Therefore, the practicality of doing Leishmania-sand fly research, particularly transmission work, is such that some parasite-vector combinations are favored over others. Some sand flies are easier to rear than others, for example, $L u$. Longipalpis is a sand fly that can be reared in relatively large numbers - although this is still far from trivial. Similarly, one may opt to use certain sand flies for other biological traits such as their ability to bite experimental animals, to survive egg laying, and re-feed when infectious (e.g., P. duboscqi vs. P. papatasi) - all of which can dictate the feasibility an experiment. From the perspective of PSG, although its role in infection appears to be relevant to many Leishmania species transmitted from natural or unnatural sand fly hosts, we favor L. mexicana in Lu. Longipalpis, an experimental combination, as our workhorse model because it generates large infections and efficiently transmits to mice. Personally, I do not see that using experimental Leishmania- 
sand fly combinations should be a barrier to Leishmania research. Quite the opposite, I feel that they can offer good models for exploring new hypotheses regarding transmission or the biology of the parasite-vector interaction. However, when researchers wish to extrapolate their lab experiments to the situation in the field, and comment on the epidemiology of specific leishmaniases, then it would be advisable to use relevant combinations. Having said that, for the reasons given above it is not always possible to do so. At the end of the day transmission by bite, irrespective of the sand fly used, can still be very revealing if it is interpreted correctly.

\section{CONCLUDING REMARKS}

There is still much to learn about leishmaniasis by studying natural infection by sand fly bite. Leishmania PPGs and PSG are an important part of Leishmania transmission and infection, however, its presence is largely ignored (Costa et al., 2011). There is an urgent need for Leishmania vaccines and the earliest opportunity

\section{REFERENCES}

Ampuero, J., Macêdo, V., and Marsden, P. (2006). Clinical findings of tegumentary leishmaniasis in children under five years of age in an endemic area of Leishmania (Viannia) braziliensis. Rev. Soc. Bras. Med. Trop. 39, 22-26.

Anderson, R. A., Knols, B. G., and Koella, J. C. (2000). Plasmodium falciparum sporozoites increase feedingassociated mortality of their mosquito hosts Anopheles gambiae s.l. Parasitology 120, 329-333.

Anderson, R. A., Koella, J. C., and Hurd, H. (1999). The effect of Plasmodium yoelii nigeriensis infection on the feeding persistence of Anopheles stephensi Liston throughout the sporogonic cycle. Proc. R. Soc. Lond. B Biol. Sci. 266, 1729-1733.

Ashford, R. W., Kohestany, K. A., and Karimzad, M. A. (1992). Cutaneous leishmaniasis in Kabul: observations on a "prolonged epidemic". Ann. Trop. Med. Parasitol. 86, 361-371.

Barral, A., Carvalho, E. M., Badaro, R., and Barral-Netto, M. (1986). Suppression of lymphocyte proliferative responses by sera from patients with American visceral leishmaniasis. Am. J. Trop. Med. Hyg. 35, 735-742.

Bates, P. A. (2007). Transmission of Leishmania metacyclic promastigotes by phlebotomine sand flies. Int J. Parasitol. 37, 1097-1106.

Beach, R., Kiilu, G., and Leeuwenburg, J. (1985). Modification of sand fly biting behavior by Leishmania leads to increased parasite transmission. Am. J. Trop. Med. Hyg. 34, 278-282.

Belkaid, Y., Kamhawi, S., Modi, G., Valenzuela, J., Noben-Trauth, N., Rowton, E., Ribeiro, J., and Sacks, D.
L. (1998). Development of a natural model of cutaneous leishmaniasis: powerful effects of vector saliva and saliva preexposure on the long-term outcome of Leishmania major infection in the mouse ear dermis. J. Exp. Med. 188, 1941-1953.

Belkaid, Y., Valenzuela, J. G., Kamhawi, S., Rowton, E., Sacks, D. L., and Ribeiro, J. M. (2000). Delayedtype hypersensitivity to Phlebotomus papatasi sand fly bite: an adaptive response induced by the fly? Proc. Natl. Acad. Sci. U.S.A. 97, 6704-6709.

Bertho, A. L., Santiago, M. A., and Coutinho, S. G. (1994). An experimental model of the production of metastases in murine cutaneous leishmaniasis. J. Parasitol. 80, 93-99.

Bogdan, C. (2001). Nitric oxide and the immune response. Nat. Immunol. 2, 907-916.

Bomfim, G., Nascimento, C., Costa, J., Carvalho, E. M., Barral-Netto, M., and Barral, A. (1996). Variation of cytokine patterns related to therapeutic response in diffuse cutaneous leishmaniasis. Exp. Parasitol. 84, 188-194.

Bousslimi, N., Aoun, K., Ben-Abda, I., Ben-Alaya-Bouafif, N., Raouane, M., and Bouratbine, A. (2010). Epidemiologic and clinical features of cutaneous leishmaniasis in southeastern Tunisia. Am. J. Trop. Med. Hyg. 83, 1034-1039.

Bretscher, P. A., Wei, G., Menon, J. N., and Bielefeldt-Ohmann, H. (1992). Establishment of stable, cellmediated immunity that makes "susceptible" mice resistant to Leishmania major. Science 257, 539-542. Regulation of immune responses by
Bronte, V., and Zanovello, P. (2005).

is to interrupt mammalian infection immediately following an infected bite, whilst the parasites are establishing infection in the skin. Despite the generation of numerous experimental formulations only two have been tested against infected sand fly bite and in both cases radically different outcomes to needle-based challenge were observed (Rogers et al., 2006; Peters et al., 2009). Because of the uniqueness of sand fly transmission more effort should be made to use sand flies as vectors of leishmaniasis and not rely entirely on needles for parasite delivery (Costa et al., 2011).

An old English proverb says that, "a hungry fly bites sore" (Heywood, 1562). Given the profound role of PPGs and PSG for Leishmania transmission this is certainly true for infected sand flies.

\section{ACKNOWLEDGMENTS}

The Biotechnology and Biological Sciences Research Council (BBSRC) and Wellcome Trust UK supported this work.

L-arginine metabolism. Nat. Rev. Immunol. 5, 641-654.

Choi, B. S., Martinez-Falero, I. C. Corset, C., Munder, M., Modolell, M., Müller, I., and Kropf, P. (2009). Differential impact of L-arginine deprivation on the activation and effector functions of $\mathrm{T}$ cells and macrophages. J. Leukoc. Biol. 85, 268-277.

Chung, H. L., Feng, L. C., and Feng, S. L. (1951). Observations concerning the successful transmission of kala-azar in North China by the bites of naturally infected Phlebotomus chinensis. Peking Nat. Hist. Bull. 19, 302-326.

Costa, C. H., Peters, N. C., Maruyama, S. R., de Brito, E. C. Jr., and Santos, I. K. (2011). Vaccines for the leishmaniases: proposals for a research agenda. Working group on research priorities for development of leishmaniasis vaccines. PLoS Negl. Trop. Dis. 29, e943. doi:10.1371/journal.pntd.0000943

Coutinho-Abreu, I. V., Sharma, N. K., Robles-Murguia, M., and Ramalho-Ortigao, M. (2010). Targeting the midgut secreted PpChitl reduces Leishmania major development in its natural vector, the sand fly Phlebotomus papatasi. PLoS Negl. Trop. Dis. 30, e901. doi:10.1371/journal.pntd.0000901

Davies, C. R. (1990). Interrupted feeding of blood-sucking insects: causes and effects. Parasitol. Today (Regul. Ed.) 6, 19-22.

Doherty, T. M., and Coffman, R. L. (1996). Leishmania major: effect of infectious dose on $\mathrm{T}$ cell subset development in BALB/c mice. Exp. Parasitol. 84, 124-135.

Dougall, A. M., Alexander, B., Holt, D. C., Harris, T., Sultan, A. H.,
Bates, P. A., Rose, K., and Walton, S. F. (2011). Evidence incriminating midges (Diptera: Ceratopogonidae) as potential vectors of Leishmania in Australia. Int. J. Parasitol. 41, 571-579.

El Kasmi, K. C., Qualls, J. E., Pesce, J. T., Smith, A. M., Thompson, R. W., Henao-Tamayo, M., Basaraba, R. J., König, T., Schleicher, U., Koo, M. S., Kaplan, G., Fitzgerald, K. A., Tuomanen, E. I., Orme, I. M., Kanneganti, T. D., Bogdan, C., Wynn, T. A., and Murray, P. J. (2008). Toll-like receptor-induced arginase 1 in macrophages thwarts effective immunity against intracellular pathogens. Nat. Immunol. 9, 1399-1406.

Evans, T. G., Teixeira, M. J., McAuliffe, I. T., Vasconcelos, I., Vasconcelos, A. W., Sousa Ade, A., Lima, J. W., and Pearson, R. D. (1992). Epidemiology of visceral leishmaniasis in northeast Brazil. J. Infect. Dis. 166, 1124-1132.

Gidwani, K., Picado, A., Rijal, S., Singh, S. P., Roy, L., Volfova, V., Andersen, E. W., Uranw, S., Ostyn, B., Sudarshan, M., Chakravarty, J., Volf, P., Sundar, S., Boelaert, M., and Rogers, M. E. (2011). Serological markers of sand fly exposure to evaluate insecticidal nets against visceral leishmaniasis in India and Nepal: a cluster-randomized trial. PLoS Negl. Trop. Dis. 5, e1296. doi:10.1371/journal.pntd.0001296

Gossage, S. M., Rogers, M. E., and Bates P. A. (2003). Two separate growth phases during the development of Leishmania in sand flies: implications for understanding the life cycle. Int. J. Parasitol. 33, 1027-1034. 
Hall, L. R., and Titus, R. G. (1995). Sand fly vector saliva selectively modulates macrophage functions that inhibit killing of Leishmania major and nitric oxide production. J. Immunol. 155, 3501-3506.

Heywood, J. (1562). The Proverbs and Epigrams of John Heywood, A. D. 1562. London: Google eBook.

Ho, M., Koech, D. K., Iha, D. W., and Bryceson, A. D. (1983). Immunosuppression in Kenyan visceral leishmaniasis. Clin. Exp. Immunol. 51, 207-214.

Hurd, H. (2003). Manipulation of medically important insect vectors by their parasites. Annu. Rev. Entomol. 48, 141-161.

Ilg, T. (2000). Proteophosphoglycans of Leishmania. Parasitol. Today (Regul. Ed.) 16, 489-497.

Ilg, T., Stierhof, Y. D., Craik, D., Simpson, R., Handman, E., and Bacic, A. (1996). Purification and structural characterization of a filamentous, mucin-like proteophosphoglycan secreted by Leishmania parasites. J. Biol. Chem. 271, 21583-21596.

Ilg, T., Stierhof, Y. D., Wiese, M., McConville, M. J., and Overath, P. (1994). Characterization of phosphoglycan-containing secretory products of Leishmania. Parasitology 108(Suppl.), S63-S71.

Jenni, L., Molyneux, D. H., Livesey, J. L., and Galun, R. (1980). Feeding behavior of tsetse flies infected with salivarian trypanosomes. Nature 283, 383-385.

Kamhawi, S., Belkaid, Y., Modi, G., Rowton, E., and Sacks, D. L. (2000). Protection against cutaneous leishmaniasis resulting from bites of uninfected sand flies. Science 290, 1351-1354.

Killick-Kendrick, R. (1979). "Biology of Leishmania in phlebotomine sand flies," in Biology of the Kinetoplastida, Vol. 2, eds W. H. R. Lumsden and D. A. Evans (New York: Academic Press), 395-460.

Killick-Kendrick, R., Leaney, A. J., Ready, P. D., and Molyneux, D. H. (1977). Leishmania in phlebotomid sandflies. IV. The transmission of Leishmania mexicana amazonensis to hamsters by the bite of experimentally infected Lutzomyia longipalpis. Proc. R. Soc. Lond. B Biol. Sci. 196, 105-115.

Killick-Kendrick, R., Wallbanks, K. R., Molyneux, D. H., and Lavin, D. R. (1988). The ultrastructure of Leishmania major in the foregut and proboscis of Phlebotomus papatasi. Parasitol. Res. 74, 586-590.
Kimblin, N., Peters, N., Debrabant, A., Secundino, N., Egen, J., Lawyer, P., Fay, M. P., Kamhawi, S., and Sacks, D. (2008). Quantification of the infectious dose of Leishmania major transmitted to the skin by single sand flies. Proc. Natl. Acad. Sci. U.S.A. 105, 10125-10130.

Klowden, M. J., and Lea, A. O. (1979). Effect of defensive host behavior on the blood meal size and feeding success of natural populations of mosquitoes (Diptera: Culicidae). J. Med. Entomol. 15, 514-517.

Koella, J. C., Sorensen, F. L., and Anderson, R. A. (1998). The malaria parasite, Plasmodium falciparum, increases the frequency of multiple feeding of its mosquito vector, Anopheles gambiae. Proc. Biol. Sci. 265, 763-768.

Kropf, P., Baud, D., Marshall, S. E., Munder, M., Mosley, A., Fuentes, J. M., Bangham, C. R., Taylor, G. P., Herath, S., Choi, B. S., Soler, G., Teoh, T., Modolell, M., and Müller, I. (2007). Arginase activity mediates reversible $\mathrm{T}$ cell hyporesponsiveness in human pregnancy. Eur. J. Immunol. 37, 935-945.

Kropf, P., Freudenberg, M. A., Modolell, M., Price, H. P., Herath, S., Antoniazi, S., Galanos, C., Smith, D. F., and Müller, I. (2004). Tolllike receptor 4 contributes to efficient control of infection with the protozoan parasite Leishmania major. Infect. Immun. 72, 1920-1928.

Kropf, P., Fuentes, J. M., Fähnrich, E., Arpa, L., Herath, S., Weber, V., Soler, G., Celada, A., Modolell, M., and Müller, I. (2005). Arginase and polyamine synthesis are key factors in the regulation of experimental leishmaniasis in vivo. FASEB J. 19, 1000-1002.

Lane, R. P. (1993). "Sandflies (Phlebotominae)," in Medical Insects and Arachnids, eds R. P. Lane and R. W. Crosskey (London: Chapman and Hall), 78-119.

Lang, T., Warburg, A., Sacks, D. L., Croft, S. L., Lane, R. P., and Blackwell, J. M. (1991). Transmission and scanning EM-immunogold labelling of Leishmania major lipophosphoglycan in the sand fly Phlebotomus papatasi. Eur. J. Cell Biol. 55, 362-372.

Lawyer, P. G., Ngumbi, P. M., Anjili, C. O., Odongo, S. O., Mebrahtu, Y. B., Githure, J. I., Koech, D. K., and Roberts, C. R. (1990). Development of Leishmania major in Phlebotomus duboscqi and Sergentomyia schwetzi (Diptera: Psychodidae). Am. J. Trop. Med. Hyg. 43, 31-43.
Lawyer, P. G., Young, D. G., Butler, J. F., and Akin, D. E. (1987). Development of Leishmania mexicana in Lutzomyia diabolica and Lutzomyia shannoni (Diptera: Psychodidae). J. Med. Entomol. 24 347-355.

Maia, C., Seblova, V., Sadlova, J., Votypka, J., and Volf, P. (2011). Experimental transmission of Leishmania infantum by two major vectors: a comparison between a viscerotropic and a dermotropic strain. PLoS Negl. Trop. Dis. 5, e1181. doi:10.1371/journal.pntd.0001181

Mbow, M. L., Bleyenberg, J. A., Hall, L. R., and Titus, R. G. (1998). Phlebotomus papatasi sand fly salivary gland lysate downregulates a Th1:but up-regulates a Th2:response in mice infected with Leishmania major. J. Immunol. 161, 5571-5577.

Milleron, R. S., Ribeiro, J. M., Elnaime, D., Soong, L., and Lanzaro, G. C. (2004). Negative effect of antibodies against maxadilan on the fitness of the sand fly vector of American visceral leishmaniasis. Am. J. Trop. Med. Hyg. 70, 278-285.

Modolell, M., Choi, B. S., Ryan, R. O. Hancock, M., Titus, R. G., Abebe, T., Hailu, A., Müller, I., Rogers, M. E., Bangham, C. R., Munder, M. and Kropf, P. (2009). Local suppression of $\mathrm{T}$ cell responses by arginase-induced L-arginine depletion in nonhealing leishmaniasis. PLoS Negl. Trop. Dis. 3, e480 doi:10.1371/journal.pntd.0000480

Molyneux, D. H., and Jefferies, D. (1986). Feeding behavior of pathogen-infected vectors. Parasitology 92, 721-736.

Monteiro, M. C., Lima, H. C., Souza, A. A., Titus, R. G., Romão, P. R. and Cunha, F. Q. (2007). Effect of Lutzomyia longipalpis salivary gland extracts on leukocyte migration induced by Leishmania major. Am. J. Trop. Med. Hyg. 76, 88-94.

Müller, I., Munder, M., Kropf, P., and Hänsch, G. M. (2009). Polymorphonuclear neutrophils and $\mathrm{T}$ lymphocytes: strange bedfellows or brothers in arms? Trends Immunol. 30, 522-530.

Munder, M., Choi, B. S., Rogers, M., and Kropf, P (2009). L-arginine deprivation impairs Leishmania majorspecific T-cell responses. Eur. J. Immunol. 39, 2161-2172.

Munder, M., Mollinedo, F., Calafat, J., Canchado, J., Gil-Lamaignere, C., Fuentes, J. M., Luckner, C., Doschko, G., Soler, G., Eichmann, K., Müller, F. M., Ho, A. D., Goerner, M., and Modolell, M. (2005). Arginase
I is constitutively expressed in human granulocytes and participates in fungicidal activity. Blood 105, 2549-2556.

Munder, M., Schneider, H., Luckner, C., Giese, T., Langhans, C. D., Fuentes, J. M., Kropf, P., Mueller, I., Kolb, A., Modolell, M., and Ho, A. D. (2006). Suppression of T-cell functions by human granulocyte arginase. Blood 108, 1627-1634.

Myskova, J., Svobodova, M., Beverley, S. M., and Volf, P. (2007). A lipophosphoglycan-independent development of Leishmania in permissive sand flies. Microbes Infect. 9 , 317-324.

Norsworthy, N. B., Sun, J., Elnaiem, D., Lanzaro, G., and Soong, L. (2004). Sand fly saliva enhances L. amazonensis infection by modulating IL10 production. Infect. Immun. 72 , 1240-1247.

Nylen, S., and Sacks, D. (2007). Interleukin-10 and the pathogenesis of human visceral leishmaniasis. Trends Immunol. 28, 378-384.

Peters, N. C., Egen, J. G., Secundino, N., Debrabant, A., Kimblin, N. Kamhawi, S., Lawyer, P., Fay, M. P. Germain, R. N., and Sacks, D. (2008). In vivo imaging reveals an essential role for neutrophils in leishmaniasis transmitted by sand flies. Science 321, 970-974.

Peters, N. C., Kimblin, N., Secundino, N., Kamhawi, S., Lawyer, P., and Sacks, D. L. (2009). Vector transmission of Leishmania abrogates vaccine-induced protective immunity. PLoS Pathog. 5, e1000484. doi:10.1371/journal.ppat.1000484

Picado, A., Singh, S. P., Rijal, S., Sundar, S., Ostyn, B., Chappuis, F., Uranw S., Gidwani, K., Khanal, B., Rai, M., Paudel, I. S., Das, M. L., Kumar, R., Srivastava, P., Dujardin, J. C., Vanlerberghe, V., Andersen, E. W., Davies, C. R., and Boelaert, M. (2010). Longlasting insecticidal nets for prevention of Leishmania donovani infection in India and Nepal: paired cluster randomised trial. BMJ 341 , c6760.

Rioux, J. A., Lanotte, G., Croset, H., Houin, R., Guy, Y., and Dedet, J. P. (1972). Ecology of leishmaniasis in the south of France. 3. Comparative receptivity of $P$ hlebotomus ariasi Tonnoir 1921 and Rhipicephalus turianicus Pomerancev and Matikasvili, 1940 to Leishmania donovani (Laveran and Mesnil, 1903). Ann. Parasitol. Hum. Comp. 47, 147-157.

Rodriguez, P. C., Quiceno, D. G., and Ochoa, A. C. (2007). L-arginine 
availability regulates T-lymphocyte cell-cycle progression. Blood 109, 1568-1573.

Rodriguez, P. C., Quiceno, D. G., Zabaleta, J., Ortiz, B., Zea, A. H., Piazuelo, M. B., Delgado, A., Correa, P., Brayer, J., Sotomayor, E. M., Antonia, S., Ochoa, J. B., and Ochoa, A. C. (2004). Arginase I production in the tumor microenvironment by mature myeloid cells inhibits Tcell receptor expression and antigenspecific T-cell responses. Cancer Res. 64, 5839-5849.

Rodriguez, P. C., Zea, A. H., Culotta, K. S., Zabaleta, J., Ochoa, J. B., and Ochoa, A. C. (2002). Regulation of $\mathrm{T}$ cell receptor CD3zeta chain expression by L-arginine. J. Biol. Chem. 277, 21123-21129.

Rodriguez, P. C., Zea, A. H., DeSalvo, J., Culotta, K. S., Zabaleta, J., Quiceno, D. G., Ochoa, J. B., and Ochoa, A. C. (2003). L-arginine consumption by macrophages modulates the expression of $\mathrm{CD} 3$ zeta chain in $\mathrm{T}$ lymphocytes. J. Immunol. 171, 1232-1239.

Rogers, M., Corware, K., Müller, I., and Bates, P. (2010). Leishmania infantum proteophosphoglycans regurgitated by the bite of its natural sand fly vector, Lutzomyia longipalpis, promote parasite establishment in mouse skin and skin-distant tissues. Microbes Infect. 12, 875-879.

Rogers, M. E., and Bates, P. A. (2007). Leishmania manipulation of sand fly feeding behavior results in enhanced transmission. PLoS Pathog. 3, e91. doi:10.1371/journal.ppat.0030091

Rogers, M. E., Chance, M. L., and Bates, P. A. (2002). The role of promastigote secretory gel in the origin and transmission of the infective stage of Leishmania mexicana by the sandfly Lutzomyia longipalpis. Parasitology 124, 495-507.

Rogers, M. E., Hajmová, M., Joshi, M. B., Sadlova, J., Dwyer, D. M., Volf, P., and Bates, P. A. (2008). Leishmania chitinase facilitates colonization of sand fly vectors and enhances transmission to mice. Cell. Microbiol. 10, 1363-1372.

Rogers, M. E., Ilg, T., Nikolaev, A. V., Ferguson, M. A., and Bates, P. A. (2004). Transmission of cutaneous leishmaniasis by sand flies is enhanced by regurgitation of fPPG. Nature 430, 463-467.

Rogers, M., Kropf, P., Choi, B. S., Dillon, R., Podinovskaia, M., Bates, P., and Müller I. (2009). Proteophosophoglycans regurgitated by Leishmania-infected sand flies target the L-arginine metabolism of host macrophages to promote parasite survival. PLoS Pathog. 5, el000555. doi:10.1371/journal.ppat.1000555

Rogers, M. E., Sizova, O. V., Ferguson, M. A., Nikolaev, A. V., and Bates, P. A. (2006). Synthetic glycovaccine protects against the bite of Leishmania-infected sand flies. J. Infect. Dis. 194, 512-518.

Rossignol, P. A., Ribeiro, J. M. C., and Spielman, A. (1984). Increased intradermal probing time in sporozoiteinfected mosquitoes. Am. J. Trop. Med. Hyg. 33, 17-20.

Rotondo, R., Bertolotto, M., Barisione, G., Astigiano, S., Mandruzzato, S., Ottonello, L., Dallegri, F., Bronte, V., Ferrini, S., and Barbieri, O. (2011). Exocytosis of azurophil and arginase 1 -containing granules by activated polymorphonuclear neutrophils is required to inhibit $\mathrm{T}$ lymphocyte proliferation. J. Leukoc. Biol. 89, 721-727.

Sacks, D. L., and Kamhawi, S. (2001). Molecular aspects of parasite-vector and vector-host interactions in leishmaniasis. Annu. Rev. Microbiol. 55, 453-483.

Sacks, D. L., Lal, S. L., Shrivastava, S. N., Blackwell, J., and Neva, F. A. (1987). An analysis of $\mathrm{T}$ cell responsiveness in Indian kala-azar. J. Immunol. 138, 908-913.

Sacks, D. L., Modi, G., Rowton, E., Späth, G., Epstein, L., Turco, S. J., and Beverley, S. M. (2000). The role of phosphoglycans in Leishmania-sand fly interactions. Proc. Natl. Acad. Sci. U.S.A. 97, 406-411.

Sakthianandeswaren, A., Elso, C. M., Simpson, K., Curtis, J. M., Kumar, B., Speed, T. P., Handman, E., and Foote, S. J. (2005). The wound repair response controls outcome to cutaneous leishmaniasis. Proc. Natl. Acad. Sci. U.S.A. 102, 15551-15556.

Sant'Anna, M. R., Diaz-Albiter, H., Mubaraki, M., Dillon, R. J., and Bates, P. A. (2009). Inhibition of trypsin expression in Lutzomyia longipalpis using RNAi enhances the survival of Leishmania. Parasit. Vectors 2,62 .

Schenkel, K., Rijal, S., Koirala, S., Koirala, S., Vanlerberghe, V., Van der Stuyft, P., Gramiccia, M., and Boelaert, M. (2006). Visceral leishmaniasis in southeastern Nepal: a cross-sectional survey on Leishmania donovani infection and its risk factors. Trop. Med. Int. Health 11, 1792-1799.

Schleicher, U., Liese, J., Knippertz, I., Kurzmann, C., Hesse, A., Heit, A., Fischer, J. A., Weiss, S., Kalinke, U., Kunz, S., and Bogdan, C. (2007). NK cell activation in visceral leishmaniasis requires TLR9:myeloid DCs, and IL-12:but is independent of plasmacytoid DCs. J. Exp. Med. 204, 893-906.

Schlein, Y., Jacobson, R. L., and Messer G. (1992). Leishmania infections damage the feeding mechanism of the sand fly vector and implement parasite transmission by bite. Proc. Natl. Acad. Sci. U.S.A. 89, 9944-9948.

Secundino, N., Kimblin, N., Peters, N. C., Lawyer, P., Capul, A. A., Beverley, S. M., Turco, S. J., and Sacks, D. (2010). Proteophosphoglycan confers resistance of Leishmania major to midgut digestive enzymes induced by blood feeding in vector sand flies. Cell. Microbiol. 12, 906-918.

Shortt, H. E., Smith, R., Swaminath, C. and Krishnan, K. (1931). Transmission of Indian kala-azar by the bite of Phlebotomus argentipes. Indian J. Med. Res. 18, 1373-1375.

Shortt, H. E., and Swaminath, C. S. (1928). The method of feeding of Phlebotomus argentipes with relation to its bearing on the transmission of kala-azar. Indian J. Med. Res. 15 827-836.

Singh, S. P., Picado, A., Boelaert, M., Gidwani, K., Andersen, E. W., Ostyn, B., Meheus, F., Rai, M., Chappuis, F. Davies, C., and Sundar, S. (2010). The epidemiology of Leishmania donovani infection in high transmission foci in India. Trop. Med. Int Health 15, 12-20.

Sippel, T. R., White, J., Nag, K., Tsvankin, V., Klaassen, M., KleinschmidtDeMasters, B. K., and Waziri, A. (2011). Neutrophil degranulation and immunosuppression in patients with GBM: restoration of cellular immune function by targeting arginase I. Clin. Cancer Res. 17, 6992-7002.

Stamper, L. W., Patrick, R. L., Fay, M. P., Lawyer, P. G., Elnaiem, D. E., Secundino, N., Debrabant, A., Sacks, D. L., and Peters, N C. (2011). Infection parameters in the sand fly vector that predict transmission of Leishmania major. PLoS Negl. Trop. Dis. 5, el288. doi:10.1371/journal.pntd.0001288

Stenger, S., Donhauser, N., Thüring, H., Röllinghoff, M., and Bogdan, C. (1996). Reactivation of latent leishmaniasis by inhibition of inducible nitric oxide synthase. J. Exp. Med. 183, 1501-1514.

Stierhof, Y. D., Bates, P. A., Jacobson, R. L., Rogers, M. E., Schlein, Y., Handman, E., and Ilg, T. (1999). Filamentous proteophosphoglycan secreted by Leishmania promastigotes forms gel-like three-dimensional networks that obstruct the digestive tract of infected sandfly vectors. Eur. J. Cell Biol. 78, 675-689.

Stierhof, Y. D., Ilg, T., Russell, D. G., Hohenberg, H., and Overath, P. (1994). Characterization of polymer release from the flagellar pocket of Leishmania mexicana promastigotes. J. Cell Biol. 125, 321-331.

Svárovská, A., Ant, T. H., Seblová, V., Jecná, L., Beverley, S. M., and Volf, P. (2010). Leishmania major glycosylation mutants require phosphoglycans (lpg2-) but not lipophosphoglycan (lpg1-) for survival in permissive sand fly vectors. PLoS Negl. Trop. Dis. 4, e580. doi:10.1371/journal.pntd.0000580

Thomas, F., Adamo, S., and Moore, J. (2005). Parasitic manipulation: where are we and where should we go? Behav. Processes 68, 185-199.

Tominaga, S. (1989). A putative protein of a growth specific cDNA from $\mathrm{BALB} / \mathrm{c}-3 \mathrm{~T} 3$ cells is highly similar to the extracellular portion of mouse interleukin 1 receptor. FEBS Lett. 258, 301-304

Tripet, F., Clegg, S., Elnaiem, D. E., and Ward, R. D. (2009). Cooperative blood-feeding and the function and implications of feeding aggregations in the sand fly, Lutzomyia longipalpis (Diptera: Psychodidae). PLoS Negl. Trop. Dis. 3, e503. doi:10.1371/journal.pntd.0000503

Volf, P., Hajmova, M., Sadlova, J., and Votypka, J. (2004). Blocked stomodeal valve of the insect vector: similar mechanism of transmission in two trypanosomatid models. Int. J. Parasitol. 34 1221-1227.

Walters, L. L., Modi, G. B., Chaplin, G. L., and Tesh, R. B. (1989a). Ultrastructural development of Leishmania chagasi in its vector, Lutzomyia longipalpis (Diptera: Psychodidae). Am. J. Trop. Med. Hyg. 41, 295-317.

Walters, L. L., Chaplin, G. L., Modi, G. B., and Tesh, R. B. (1989b) Ultrastructural biology of Leishmania (Viannia) panamensis (=Leishmania braziliensis panamensis) in Lutzomyia gomezi (Diptera: Psychodidae): a natural host-parasite association. Am. J. Trop. Med. Hyg. 40, 19-39.

Walters, L. L., Modi, G. B., Tesh, R. B., and Burrage, T. (1987). Hostparasite relationship of Leishmania mexicana mexicana and Lutzomyia abonnenci (Diptera: Psychodidae). Am. J. Trop. Med. Hyg. 36, 294-314. 
Warburg, A., Hamada, G. S., Schlein, Y., and Shire, D. (1986). Scanning electron microscopy of Leishmania major in Phlebotomus papatasi. Z. Parasitienkd 72, 423-431.

Warburg, A., and Schlein, Y. (1986). The effect of post-bloodmeal nutrition of Phlebotomus papatasi on the transmission of Leishmania major. Am. J. Trop. Med. Hyg. 35, 926-930.

Wei, X., Charles, I. G., Smith, A., Ure, J., Feng, G., Huang, F., Xu, D., Müller, W., Moncada, S., and Liew, F. Y. (1995). Altered immune responses in mice lacking inducible nitric oxide synthase. Nature 375, 408-411.

Whitaker, S. M., Colmenares, M. Pestana, K. G., and McMahonPratt, D. (2008). Leishmania pifanoi proteoglycolipid complex P8 induces macrophage cytokine production through Toll-like receptor 4. Infect. Immun. 76, 2149-2156.

WHO. (2010). Control of the Leishmaniasis: Report of a Meeting of the WHO. Expert Committee on the Control of Leishmaniases. WHO Technical Report Series N949. Geneva: WHO.
Wortmann, G. W., Aronson, N. E., Miller, R. S., Blazes, D., and Oster, C. N. (2000). Cutaneous leishmaniasis following local trauma: a clinical pearl. Clin. Infect. Dis. 31, 199-201.

Conflict of Interest Statement: The author declares that the research was conducted in the absence of any commercial or financial relationships that could be construed as a potential conflict of interest.

Received: 07 February 2012; accepted: 31 May 2012; published online: 28 June 2012.
Citation: Rogers ME (2012) The role of Leishmania proteophosphoglycans in sand fly transmission and infection of the mammalian host. Front. Microbio. 3:223. doi: 10.3389/fmicb.2012.00223

This article was submitted to Frontiers in Microbial Immunology, a specialty of Frontiers in Microbiology.

Copyright (c) 2012 Rogers. This is an open-access article distributed under the terms of the Creative Commons Attribution Non Commercial License, which permits non-commercial use, distribution, and reproduction in other forums, provided the original authors and source are credited. 